\title{
Epiphytic Bacteria Alter Floral Scent Emissions
}

\author{
Carola Helletsgruber $^{1} \cdot$ Stefan Dötterl $^{1} \cdot$ Ulrike Ruprecht $^{1} \cdot$ Robert R. Junker $^{1}$
}

Received: 19 June 2017 /Revised: 17 October 2017 / Accepted: 20 October 2017 / Published online: 14 November 2017

(C) The Author(s) 2017. This article is an open access publication

\begin{abstract}
Floral scents are key mediators of biotic interactions between flowers and various organisms such as pollinators, antagonistic animals and bacteria. It has been shown that emissions of floral volatiles are influenced by interactions with other organisms at the levels of roots, leaves and flowers. However, it is largely unknown whether and how epiphytic bacteria associated with flowers affect the composition of floral scent. By comparing volatiles of sterile and inoculated plants we found that bacteria may add components, induce or reduce the emission of compounds, and potentially catabolize others. These mechanisms collectively altered the floral scent emission and led to clearly different compositions. Our results confirm that bacteria have the potential to interfere with flower-animal interactions with consequences for pollination and plant reproduction.
\end{abstract}

Keywords Brassica rapa $\cdot$ Epiphytic bacteria $\cdot$ Floral scent . Microbiome $\cdot$ Volatile organic compounds $\cdot$ Sterile plants

\section{Introduction}

Volatile organic compounds (VOCs) released by flowers are key mediators of biotic interactions with pollinators, antagonistic animals, and bacteria (Junker 2016). These diverse partners do not only behaviorally or physiologically respond to floral scent emissions, they also affect the composition of floral scent, both quantitatively and qualitatively. Whereas

Robert R. Junker

robert.junker@sbg.ac.at

1 Department of Ecology and Evolution, University of Salzburg, Hellbrunnerstrasse 34, 5020 Salzburg, Austria herbivore- and pollinator-mediated changes of VOCs have been shown for a number of plant species (Junker 2016), evidence for bacterial effects is limited. A study on Sambucus nigra plants showed that flowers after treatment with antibiotics release proportionally altered and reduced emission rates of terpenes, suggesting that bacteria influence floral scent emissions (Penuelas et al. 2014). Several indirect and direct mechanisms by which bacteria may modify floral VOCs are conceivable (Junker and Tholl 2013). First, bacteria induce volatile emissions in plants in response to pathogen attack and avirulent bacterial strains (Huang et al. 2003). Second, bacteria were shown to utilize plant VOCs as carbon source, and their catabolism subsequently adds new compounds to the plants' scent (Del Giudice et al. 2008). Third, emission rates of volatiles that serve as carbon source for bacteria may strongly decrease as a consequence of bacterial consumption (Abanda-Nkpwatt et al. 2006). Finally, bacteria are known to synthesize and emit a large number of VOCs by their own metabolism independent of plant volatiles that may be used as substrate (Schulz and Dickschat 2007), and these novel compounds may contribute to the plant-specific scent. The mechanisms summarized here have been shown for bacteria associated with roots or leaves, but not for flowers that just recently came into focus as habitats for diverse bacterial colonizers. Given the importance of flowers in the plants' lifecycle and the growing evidence that bacteria associated with flowers may interfere with pollination (Vannette et al. 2012), which may have consequences for natural and agricultural systems (Aleklett et al. 2014), further information about bacterial effects on floral phenotypes is required.

In order to test the effect of bacteria on floral scent emissions, we compared VOCs of plants cultivated under sterile conditions and of plants cultivated under sterile conditions and inoculated with defined bacterial communities three days prior to floral scent collection. In addition, VOCs of non- 
sterile greenhouse grown plants were analyzed. Our study contributes to the understanding of how bacteria influence plant traits and provides a basis for future studies, testing the role of bacteria in plant-pollinator interactions and sexual plant reproduction.

\section{Methods and Materials}

Study Organisms We used fast-cycling Brassica rapa L. plants (Brassicaceae, Wisconsin Fast Plants, 1-033 Standard, Rapid-cycling Brassica collection, University of Wisconsin-Madison, Department of Plant Pathology, Madison, USA). Prior to cultivation, seeds were surfacesterilized by treating them with $70 \%$ ethanol $(2 \mathrm{~min})$ followed by sodium hypochlorite solution (7\% available chlorine) containing $0.2 \%$ Triton X-100 (8 min), followed by seven washing steps in sterile double-distilled water. Sterilized seeds were cold stratified $\left(4^{\circ} \mathrm{C}\right)$ over night. B. rapa plants were grown on a standard Murashige \& Skoog (MS) nutrient medium including vitamins (Duchefa Biochemie, Haarlem, Netherlands) supplemented with plant agar (Duchefa Biochemie, Haarlem, Netherlands) and 2\% sucrose. After autoclaving the medium, $220 \mathrm{ml}$ were filled into Microboxes (Model: TP5000 + TPD5000-18.5 × $18.5 \times 19.1 \mathrm{~cm}$; Combiness nv, Nevele, Belgium) allowing to cultivate one plant individual per box under sterile conditions. Plants were grown under long-day conditions ( $16 \mathrm{~h}$ light $-8 \mathrm{~h}$ dark) at a constant temperature of $24^{\circ} \mathrm{C}$. Additional B. rapa plants were grown in the green house (non-sterile) under long-day conditions at $20^{\circ} \mathrm{C}$ using ED73 standard soil (Einheitserde Werkverband eV, Sinntal-Altengronau, Germany) to evaluate effects of different cultivation methods on scent emission.

Bacterial strains were isolated from B. rapa flowers and leaves grown in the Botanical Garden of the University of Salzburg. Individual flowers and leaves were placed in $1 \mathrm{ml}$ autoclaved phosphate buffered saline (PBS tablet, SigmaAldrich R, Germany) using sterile forceps and were sonicated for $7 \mathrm{~min}$ to detach bacteria from plant surfaces. $50 \mu \mathrm{L}$ of the PBS containing bacteria were streaked on autoclaved R2A agar medium (Sigma-Aldrich R, Germany) containing cycloheximide (Sigma-Aldrich R, Germany; $30 \mathrm{mg} \mathrm{L}^{-1}$ ) to prevent fungal growth. After an incubation of $72 \mathrm{~h}$, six colonyforming units (cfus, three originating from flowers and three from leaves) were haphazardly selected in order to get an unbiased selection of epiphytic bacteria and were then cultivated on autoclaved LB-medium-powder (Panreac AppliChem, Germany), supplemented with Agar Bacteriology grade (Panreac AppliChem, Germany) and $1 \mathrm{~g}$ $\mathrm{L}^{-1}$ D-glucose (Sigma-Aldrich R, Germany) without fungicide. Strains were sequenced for identification. The PCR mix contained 0.6 units of GoTaq DNA polymerase (Promega), $0.2 \mathrm{nM}$ of each of the four dNTPs (Promega),
$0.3 \mu \mathrm{m}$ of each primer (Eurofins) and the bacterial cells from the respective colony. The $16 \mathrm{~S}$ rRNA gene (target regions $\mathrm{V} 3$, $\mathrm{V} 4, \sim 550 \mathrm{bp}$ ) was amplified and sequenced (forward and reverse) with two universal primers specific for members of Eubacteria 341f (5'-CCT ACG GGA GGC AGC - $3^{\prime}$ ) and 907rM (5'-CCGTCAATTCMTTTGAGTTT $\left.-3^{\prime}\right)$ with standard PCR - conditions $\left(95^{\circ} \mathrm{C}\right.$ for $2 \mathrm{~min}$ : 1 cycle; $94^{\circ} \mathrm{C}$ for $30 \mathrm{~s}, 53^{\circ} \mathrm{C}$ for $30 \mathrm{~s}, 72^{\circ} \mathrm{C}$ for $40 \mathrm{~s}: 35$ cycles). Unpurified PCR-products were sent to Eurofins Genomics (Ebersberg, Germany) for sequencing.

Prior to flowering, buds and leaves were inoculated with the mixture of the six selected bacterial strains. Prior to inoculation, each strain was individually suspended in PBS, and initial optical density $\left(\mathrm{OD}_{600}\right)$ was measured using a plate reader (Bio-Tek, BTKELx808iu), and was subsequently diluted to $\mathrm{OD}_{600}=0.2$. The six suspensions of the bacterial strains were mixed to yield a suspension with even optical densities. Note the same ODs may translate into different concentrations (cell number per volume) for different bacterial strains. Autoclaved cotton swabs were used to inoculate the plants with bacteria. Control plants (sterile) were treated with PBS in the same way.

VOC Collection and Analyses VOCs were collected from 19 sterile and eight inoculated plants, as well as from three plants grown under greenhouse conditions by using the dynamic headspace methods as described earlier (Etl et al. 2016). Three days after the inoculation individual plants in full bloom were taken out of the microboxes (including roots and agar) and were bagged in polyethylene oven bags $(7 \times 10 \mathrm{~cm}$; Toppits, Germany) under sterile conditions (sterile bench). Immediately after bagging, VOCs were trapped for $60 \mathrm{~min}$ on adsorbent tubes (quartz glass tubes: length $25 \mathrm{~mm}$; i. diam. $2 \mathrm{~mm}$ ) filled with $1.5 \mathrm{mg}$ each of Carbotrap B (mesh 20-40) and Tenax TA (mesh 60-80; both Supelco, Germany) using a membrane pump (G12/01 EB; Gardner Denver Thomas $\mathrm{GmbH}$, Fürstenfeldbruck, Germany). The flow was adjusted at $200 \mathrm{ml} / \mathrm{min}$ using a flowmeter. For control, headspace samples of empty oven bags and leaves were collected by using the same method. Samples were analyzed with a GC/MS system (QP2010Ultra, Shimadzu Corporation, Japan) coupled to a thermal desorption unit (TD-20, Shimadzu, Japan) and equipped with a ZB-5 fused silica column (5\% phenyl, 95\% dimethylpolysiloxane; $60 \mathrm{~m}$ long, i. diam. $0.25 \mathrm{~mm}$, film thickness $0.25 \mu \mathrm{m}$, Phenomenex, USA). We used a split ratio of $1: 1$ and a consistent helium carrier gas flow of $1.5 \mathrm{ml} / \mathrm{min}$. The GC oven temperature started at $40{ }^{\circ} \mathrm{C}$, then increased by $6{ }^{\circ} \mathrm{C} / \mathrm{min}$ to $250^{\circ} \mathrm{C}$ and was held for $1 \mathrm{~min}$. The MS interface worked at $250{ }^{\circ} \mathrm{C}$. Mass spectra were taken at $70 \mathrm{eV}$ (EI mode) from $\mathrm{m} / \mathrm{z} 30$ to 350 . GC/MS data were processed using the GCMSolution Version 4.11 (Shimadzu Corporation, Japan). Compounds were identified according to the NIST 11, Wiley 9, FFNSC 2, Essential Oils and Adams 2007 mass 
spectral (and retention index) databases. The identity of most of the compounds was confirmed by comparison of mass spectra and retention times with those of authentic standards. For quantitative analysis of VOCs, known amounts of monoterpenes, aliphatic, and aromatic compounds were injected into the GC/MS system, and mean peak areas were used to determine the total amount of scent (see Etl et al. 2016). After VOC sampling, bacterial abundances on flowers were checked by isolating bacterial strains from flowers as described above.

Statistical Analyses In order to test for differences in VOCs of sterile and inoculated plants, we performed a random forest analysis $\left(n_{\text {tree }}=10,000\right.$ bootstrap samples with $m_{\text {try }}=6$ compounds randomly selected at each node) using the R package randomForest. In addition, we performed a distance-based redundancy analysis as implemented in the $\mathrm{R}$ package vegan based on Bray-Curtis distances.

\section{Results and Discussion}

Of the six haphazardly selected bacterial strains, three belong to the genus Staphylococcus (BR-GH-2A, BR-GH-2B, BRGH-2C), two to the genus Bacillus (BR-GH-3-A, BR-GH-4A), and one to the genus Sphingomonas (BR-GH-4-C, NCBI GenBank accession numbers for nucleotide sequences: MF347688 - MF347693). These bacterial genera have been described to be associated with plant surfaces (Junker and Keller 2015). Bacterial abundance on inoculated flowers ranged from 340,000 to $9,620,000$ cfus (mean $\pm \mathrm{sd}$ : $4,207,500 \pm 3,215,881)$. From 11 out of 19 flowers not inoculated with the bacterial strains, no bacteria were isolated after VOC collection. From the remaining eight flowers, we isolated between 140 and 1200 cfus (mean \pm sd: $692.5 \pm 425$ ). Contamination most likely occurred during the application of PBS (control treatment) or during VOC collection.

Floral scent emissions differed between treatment groups both qualitatively and quantitatively. Sterile, inoculated, and greenhouse plants distinctly differed both in total composition (permutation test for distance-based redundancy analysis: $F_{2,27}=5.45, p<0.001$, Fig. 1 , random forest class.error: 0.05 (sterile), 0.13 (inoculated), 0.67 (greenhouse)) and in the emission rates of individual components (Table 1). Most strikingly, acetoin and 2,3-butanediol were detected in considerably higher amounts in samples inoculated with bacteria prior to VOC collection (Table. 1). Exclusively those VOC samples from flowers that were not experimentally inoculated (supposed to be 'sterile'), but were contaminated with bacteria at the time of VOC collection (eight out of nineteen) contained acetoin and / or its reduction product, 2,3-butanediol, whereas flowers cultivated under sterile conditions from which we did not isolate bacteria after VOC collection were devoid of these compounds. Consequently, bacterial origin of these compounds is suggested, though we cannot exclude that these compounds are plant emissions induced by the bacteria. Both compounds have been described as typical volatiles of bacteria and were shown to be released, among others, by Staphylococcus and Bacillus (Schulz and Dickschat 2007), supporting the hypothesis that volatiles synthesized by bacteria may well contribute to the chemical phenotype of flowers. In contrast, emission rates of e.g. 1,2-propanediol, 2,3dimethylpentanol, and longifolene were reduced in samples inoculated with bacteria (Table. 1). Our results strongly
Fig. 1 Differences in scent composition of sterile and inoculated Brassica rapa inflorescences and of those cultivated in a greenhouse. Similarity of samples returned by distance-based redundancy analysis based on Bray-Curtis distances are shown. Emission rates of compounds in the plot (triangles) are higher in those samples plotted in their direction relative to the origin

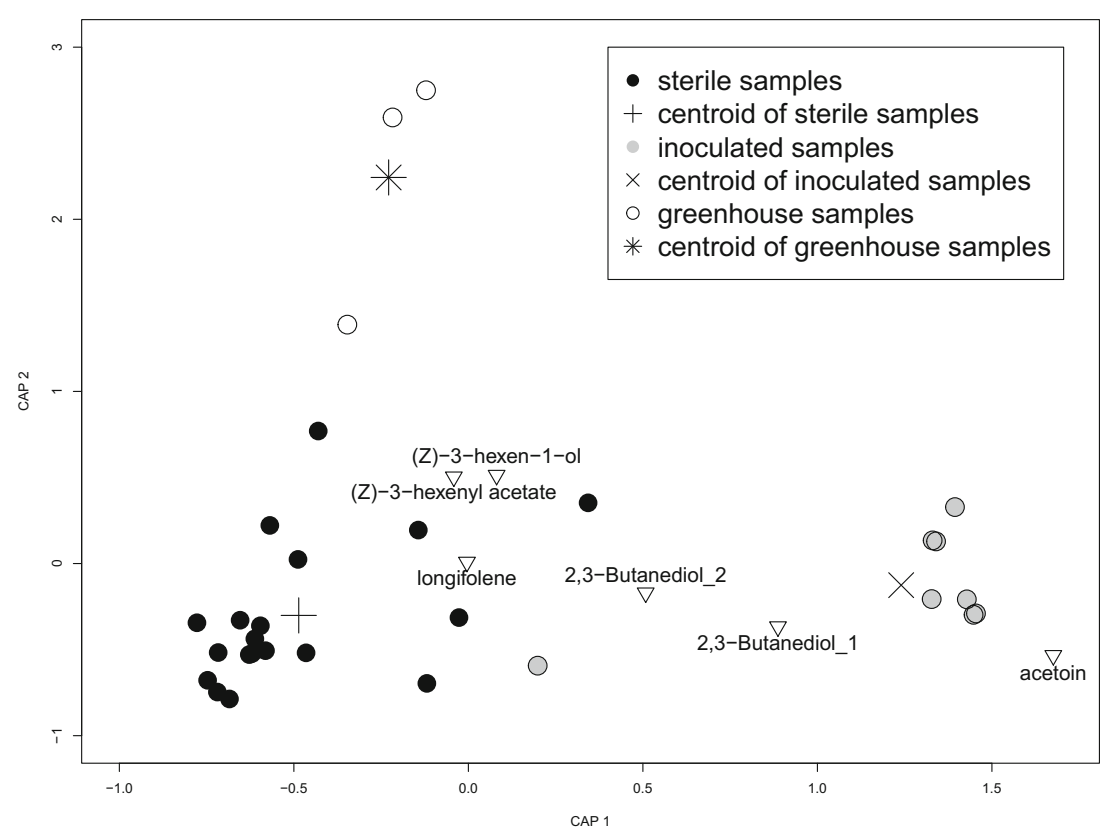


Table 1 Scent emission of sterile and inoculated Brassica rapa inflorescences and of those cultivated in a greenhouse. For each compound and treatment group mean \pm SD emission $\left[\mathrm{ng} \mathrm{h}^{-1}\right.$ inflorescence ${ }^{-1}$ ] is given. Compounds are listed by chemical class and within class sorted by retention index (RI). Variable importance $E$ (resulting from random forest analysis) is proportional to the compound's contribution to a correct assignment. Bold numbers indicate significant differences in the emission rates of these compounds between sterile and inoculated flowers ( $t$-test). Compounds marked with asterisk have been identified by using synthetic standards. For compounds with no synthetic standards available, literature data on retention indices (stationary phase: 5\% phenyl, $95 \%$ dimethylpolysiloxane) are given as footnotes

\begin{tabular}{|c|c|c|c|c|c|}
\hline RI & Compound class and name & greenhouse & sterile & inoculated & $E$ \\
\hline \multicolumn{6}{|c|}{ Aliphatic compounds } \\
\hline 684 & 2-Pentanone* & & & $1.23 \pm 1.93$ & 1.34 \\
\hline 706 & Acetoin* & $0.55 \pm 0.36$ & $6.18 \pm 18.33$ & $409.81 \pm 165.93$ & 49.75 \\
\hline 720 & Methyl butyrate* & & & $0.68 \pm 1.92$ & 0.00 \\
\hline $722^{\mathrm{a}}$ & 2-Methylbutanenitrile & & & $2.60 \pm 6.14$ & 0.90 \\
\hline $729^{\mathrm{b}}$ & 1,2-Propanediol & & $0.20 \pm 0.33$ & & 5.15 \\
\hline 771 & 2,3-Butanediol_1* & & $13.49 \pm 27.02$ & $226.40 \pm 227.99$ & 32.23 \\
\hline 782 & 2,3-Butanediol_2* & & $2.76 \pm 6.18$ & $125.05 \pm 157.83$ & 32.91 \\
\hline $797^{\mathrm{c}}$ & 2,3-Dimethylpentanol & $5.03 \pm 3.29$ & $2.69 \pm 1.62$ & $0.73 \pm 1.42$ & 12.39 \\
\hline 841 & 2-Methylbutanoic acid* & & $0.20 \pm 0.71$ & $1.31 \pm 1.83$ & 4.72 \\
\hline $849^{\mathrm{d}}$ & Ethyl 2-methylbutanoate & & & $0.08 \pm 0.18$ & 1.34 \\
\hline 854 & (Z)-3-Hexen-1-ol* & $76.98 \pm 88.11$ & $10.03 \pm 8.97$ & $34.15 \pm 39.66$ & -3.52 \\
\hline 867 & 1-Hexanol* & $1.80 \pm 3.11$ & $0.90 \pm 1.03$ & $1.37 \pm 1.63$ & -1.39 \\
\hline 943 & 3-Octanone* & $4.67 \pm 2.03$ & $16.92 \pm 11.73$ & $33.87 \pm 35.12$ & 6.20 \\
\hline $986^{\mathrm{e}}$ & 4-1sothiocyanato-1-butene & $14.84 \pm 12.92$ & $12.06 \pm 12.19$ & $21.06 \pm 20.03$ & -0.39 \\
\hline 998 & Ethyl hexanoate* & & $0.44 \pm 0.80$ & $0.59 \pm 1.14$ & -3.04 \\
\hline 1005 & (Z)-3-Hexenyl acetate* & $83.83 \pm 72.60$ & $22.55 \pm 19.00$ & $16.73 \pm 24.49$ & 2.79 \\
\hline \multicolumn{6}{|c|}{ Aromatic compounds } \\
\hline 963 & Benzaldehyde* & $25.61 \pm 17.98$ & $10.96 \pm 9.61$ & $6.08 \pm 3.65$ & 7.03 \\
\hline 1038 & Benzyl alcohol* & $2.96 \pm 0.90$ & $7.03 \pm 22.72$ & $1.37 \pm 1.13$ & 1.93 \\
\hline 1101 & Methyl benzonate* & $1.09 \pm 1.88$ & & & 0.00 \\
\hline 1118 & 2-Phenylethyl alcohol* & & $0.05 \pm 0.22$ & $0.34 \pm 0.95$ & -1.66 \\
\hline 1145 & Phenylacetonitrile* & $0.61 \pm 1.06$ & & & 0.00 \\
\hline 1169 & Benzyl acetate* & $0.24 \pm 0.22$ & $0.37 \pm 0.73$ & $0.33 \pm 0.31$ & -1.37 \\
\hline 1300 & Indole* & $2.24 \pm 3.88$ & & & 0.00 \\
\hline \multicolumn{6}{|c|}{ Terpenoids } \\
\hline 1099 & Linalool* & $0.49 \pm 0.86$ & $3.12 \pm 6.57$ & $0.34 \pm 0.65$ & 1.48 \\
\hline $1432^{\mathrm{f}}$ & Longifolene & $2.24 \pm 1.01$ & $1.33 \pm 0.94$ & $0.42 \pm 0.33$ & 23.72 \\
\hline \multicolumn{6}{|c|}{ Unknowns } \\
\hline 805 & $\mathrm{~m} / \mathrm{z}: 45,57,58,43,59,41$ & & $0.65 \pm 2.40$ & $3.68 \pm 2.84$ & 20.42 \\
\hline 936 & $\mathrm{~m} / \mathrm{z}: 115.41 .56 .57 .86 .39$ & & $1.08 \pm 1.77$ & $2.73 \pm 3.48$ & 2.63 \\
\hline 1088 & $\mathrm{~m} / \mathrm{z}: 41,70,67,126,127,99$ & & $0.51 \pm 0.77$ & $0.35 \pm 0.61$ & -2.73 \\
\hline 1130 & $\mathrm{~m} / \mathrm{z}: 113,119,45,134,73,53$ & $8.13 \pm 7.96$ & $1.84 \pm 4.51$ & $0.33 \pm 0.55$ & 3.48 \\
\hline 1217 & $\mathrm{~m} / \mathrm{z}: 56,41,114,55,70,42$ & & $0.64 \pm 0.66$ & & 18.13 \\
\hline 1228 & $\mathrm{~m} / \mathrm{z}: 56,55,41,114,70,42$ & & $1.50 \pm 0.94$ & & 45.86 \\
\hline
\end{tabular}

${ }^{a}$ RI 717, Cajka et al. 2007, J Sep Sci 30:534-546; ${ }^{\mathrm{b}}$ RI 732, Sebastian et al. 2003, Sci des Alim 23:497-511; ${ }^{\mathrm{c}}$ RI 827, King et al. 1993, J Agric Food Chem 41:1974-1981; ${ }^{\mathrm{d}}$ RI 849, Mantzouridou et al. 2006, J Agric Food Chem 54:2695-2704; ${ }^{\mathrm{e}}$ RI 984, Bergnaud et al. 2003, Int J Environ Anal Chem 83:837-849; ${ }^{\mathrm{f}}$ RI 1416, Kant et al. 2004, Plant Physiol 135:483-495

suggest that bacteria exploit certain plant VOCs as carbon source, which are, therefore, reduced in their emission rates. Other compounds that occurred exclusively (some of them occasionally) in samples of inoculated flowers (Table. 1) may also represent compounds that are produced directly by bacteria. Alternatively, they might be synthesized by the plants as a response to bacterial colonization, or be breakdown-products of plant VOCs. Samples taken from greenhouse-grown plants, which harbored a more natural bacterial community than the flowers inoculated with our 
artificial community, also differed from the experimentally treated plants (Fig. 1). These differences may be the result of different cultivation substrates (plant agar vs. soil) and growing conditions and / or differences in bacterial colonization. In the greenhouse-grown flowers we also detected acetoin (Table 1), which corresponds to the presence of bacteria in these samples. While distance-based redundancy analysis and random forest analysis both clearly separated volatile compositions of sterile and inoculated flowers, the former analysis succeeded more in separating the greenhouse samples from the sterile samples than the latter (Fig. 1, Table 1, note the small sample size of greenhouse-grown plants). However, the lack of many compounds in the greenhouse samples as well as the higher emission rates of other compounds (Table 1) demonstrate that sterile plants do emit different bouquets of VOCs than plants with a natural microbiome. Note that the bacterial communities used to inoculate the plant are not as diverse as the communities naturally associated with flowers in diversity and composition. Therefore, future studies should test the effects of natural communities. Nonetheless, our results provide first evidence that epiphytic bacteria have the potential to affect floral scent emissions.

In conclusion, our results clearly demonstrate the involvement of bacteria in shaping the scent emission of flowers. Bacterial contributions to the formation of VOCs that are perceived by both pollinators and antagonistic organisms demand a rethinking about the ecology and evolution of scent-mediated interactions between flowers and other organisms. Floral scents are crucial in initiating and maintaining flower constancy, which is prerequisite for effective pollen transfer between conspecific flowers (Borghi et al. 2017). Given that bacteria reduce, alter, or emit behaviorally relevant VOCs, these modifications of floral scent may prevent initial attraction either by reducing the emission rate of attractive compounds or by adding repellent compounds to the bouquet. Furthermore, associative learning may be hampered if scent bouquets differ between flowers due to differences in bacterial colonizers. The number of studies on possible ecological consequences of bacterial contributions to the floral phenotype is limited but our results underline that bacteria should not be overlooked when studying floral scents and the interactions they mediate.

Acknowledgements We thank the Deutsche Forschungsgemeinschaft for financial support (DFG, JU2856/1-1).

Open Access This article is distributed under the terms of the Creative Commons Attribution 4.0 International License (http:// creativecommons.org/licenses/by/4.0/), which permits unrestricted use, distribution, and reproduction in any medium, provided you give appropriate credit to the original author(s) and the source, provide a link to the Creative Commons license, and indicate if changes were made.

\section{References}

Abanda-Nkpwatt D, Musch M, Tschiersch J, Boettner M, Schwab W (2006) Molecular interaction between Methylobacterium extorquens and seedlings: growth promotion, methanol consumption, and localization of the methanol emission site. J Exp Bot 57(15):4025-4032

Adams RP. 2007. Identification of essential oil components by gas chromatography / mass spectrometry. Carol Stream, Illinois: Allured Publishing Corporation.

Aleklett K, Hart M, Shade A (2014) The microbial ecology of flowers: an emerging frontier in phyllosphere research. Botany 92:253-266

Begnaud F, Pérès C, Berdagué J-L (2003) Characterization of volatile effluents of livestock buildings by solid-phase microextraction. Int J Environ Anal Chem 83:837-849

Borghi M, Fernie AR, Schiestl FP, Bouwmeester HJ (2017) The sexual advantage of looking, smelling, and tasting good: the metabolic network that produces signals for pollinators. Trends Pl Sci 22(4): $338-350$

Cajka T, Hajslova J, Cochran J, Holadova K, Klimankova E. 2007. Solid phase microextractioncomprehensive two-dimensional gas chromatography-time-of-flight mass spectrometry for the analysis of honey volatiles. J Sep Sci 30(4):534-546.

Del Giudice L, Massardo DR, Pontieri P, Bertea CM, Mombello D, Carata E, Tredici SM, Tala A, Mucciarelli M, Groudeva VI et al (2008) The microbial community of Vetiver root and its involvement into essential oil biogenesis. Environ Microbiol 10(10):2824-2841

Etl F, Berger A, Weber A, Schonenberger J, Dötterl S (2016) Nocturnal plant bugs use $c i s$-jasmone to locate inflorescences of an Araceae as feeding and mating site. J Chem Ecol 42(4):300-304

Huang J, Cardoza YJ, Schmelz EA, Raina R, Engelberth J, Tumlinson JH (2003) Differential volatile emissions and salicylic acid levels from tobacco plants in response to different strains of Pseudomonas syringae. Planta 217(5):767-775

Junker RR (2016) Multifunctional and diverse floral scents mediate biotic interactions embedded in communities. In: Blande JD, Glinwood RT (eds) Deciphering chemical language of plant communication. Springer, Heidelberg

Junker RR, Keller A (2015) Microhabitat heterogeneity across leaves and flower organs promotes bacterial diversity. FEMS Microbiol Ecol 91:fiv097

Junker RR, Tholl D (2013) Volatile organic compound mediated interactions at the plant-microbe interface. J Chem Ecol 39:810-825

Kant MR, Ament K, Sabelis MW, Haring MA, Schuurink RC. 2004. Differential timing of spider miteinduced direct and indirect defenses in tomato plants. Plant Phys 135(1):483-495

King MF, Hamilton BL, Matthews MA, Rule DC, Field RA (1993) Isolation and identification of volatiles and condensable material in raw beef with supercritical carbon dioxide extraction. J Agric Food Chem 41:1974-1981

Mantzouridou F, Tsimidou MZ, Roukas T (2006) Performance of crude olive pomace oil and soybean oil during carotenoid production by blakeslea trispora in submerged fermentation. J Agric Food Chem 54:2695-2704

Penuelas J, Farre-Armengol G, Llusia J, Gargallo-Garriga A, Rico L, Sardans J, Terradas J, Filella I (2014) Removal of floral microbiota reduces floral terpene emissions. Sci Rep 4:6727

Schulz S, Dickschat J (2007) Bacterial volatiles: the smell of small organisms. Nat Prod Rep 24:814-842

Sebastian I, Viallon-Fernandez C, Berge P, Berdague JL. 2003. Analysis of the volatile fraction of lamb fat tissue: influence of the type of feeding. Sci Aliment 23(4):497-511

Vannette RL, Gauthier M-PL, Fukami T (2012) Nectar bacteria, but not yeast, weaken a plant-pollinator mutualism. Proc R Soc B 280: 20122601 